\title{
LEY ZAMUDIO: ¿PONDERACIÓN O SUBSUNCIÓN? COMENTARIO A LA SENTENCIA ROL No 1009-2014 DE LA CORTE DE APELACIONES DE CONCEPCIÓN
} Zamudio LaW: Weighting or subsumption? Commentary to the decision Case No 1009-2004 of the Concepción Court of Appeals Loi Zamudio: ¿Ponderation ou Subsuntion? Commentaire L’arrêt Rôle no. 1009-2014 De la Cour d’Appel de ConCePCión

Miriam Lorena Henríquez Viñas

José Ignacio NúNEZZ LeIva*

\section{INTRODUCCIÓN}

Con fecha 26 de junio de 2014, el Primer Juzgado Civil de Concepción ${ }^{1}$ dictó una sentencia que resolvió una acción de no discriminación arbitraria interpuesta por doña Tatiana Torres, en representación de su hija menor, en contra del colegio Santísima Trinidad S.A. perteneciente a una congregación religiosa católica. La requirente dedujo la acción de la Ley No $20.609^{2}$, atendida la negativa del colegio a reincorporar a su hija debido a su situación de convivencia -al momento de la solicitud-con una persona distinta del padre.

El tribunal de primera instancia acogió la acción de no discriminación arbitraria, mandó dejar sin efecto la referida negativa, dispuso que el colegio admita a la menor como alumna regular a partir del segundo semestre de 2014, y condenó al colegio al pago de una multa en beneficio fiscal de 10 Unidades Tributarias Mensuales. Contra la sentencia de primera instancia, el colegio denunciado dedujo un recurso de apelación. Del recurso de apelación conoció la Corte de Apelaciones de

\footnotetext{
*Abogada de la Universidad Nacional del Comahue, Argentina. Magíster en Derecho Público con mención en Derecho Constitucional por la Pontificia Universidad Católica de Chile. Doctor en Ciencias Jurídicas, Universidad de Santiago de Compostela, España. Profesora de Derecho Constitucional Universidad Alberto Hurtado, Santiago, Chile. Correo electrónico: mhenriqu@uahurtado.cl.

**Abogado. Licenciado en Derecho por la Pontificia Universidad Católica de Chile. Diplomado en Derechos Humanos por la Universidad Católica del Uruguay. Post Graduado en Derecho por la Universidad de Castilla La Mancha, España: Especialista en Constitucionalismo y Garantismo (2009) y Especialista en Justicia Constitucional y Procesos Constitucionales (2012). Magíster en Derecho Público por la Pontificia Universidad Católica de Chile. Diploma de Estudios Avanzados (DEA) y Doctor (C) en Derecho por la Universidad de Castilla La Mancha, España. Investigador en la Facultad de Derecho de la Universidad FinisTerrae, Santiago, Chile. Correo electrónico: jinunez@uft.cl.

${ }^{1}$ Primer Juzgado de Letras de Concepción, 26 de junio de 2014, Rol No 8228-2013.

${ }^{2}$ Ley No 20.609, establece medidas contra la discriminación, Diario Oficial, 24 de julio de 2012.
} 
Concepción ${ }^{3}$, con fecha 24 de octubre de 2014 ratificó la sentencia pronunciada por el tribunal de letras de la misma ciudad. Sobre esta última sentencia versará nuestro análisis.

Antes de comenzar, corresponde señalar que la Ley No 20.609, conocida como "Ley Zamudio", fue promulgada y publicada en julio de 2012 y estableció medidas contra la discriminación. En tal sentido, instituyó la acción de no discriminación arbitraria, siendo definida esta última como "toda distinción, exclusión o restricción que carezca de justificación razonable, efectuada por agentes del Estado o particulares, y que cause privación, perturbación o amenaza en el ejercicio legitimo de los derechos fundamentales establecidos en la Constitución Politica de la República o en los tratados internacionales sobre derechos humanos ratificados por Chile y que se encuentren vigentes, en particular cuando se funden en motivos tales como la raza o etnia, la nacionalidad, la situación socioeconómica, el idioma, la ideología u opinión política, la religión o creencia, la sindicación o participación en organizaciones gremiales o la falta de ellas, el sexo, la orientación sexual, la identidad de género, el estado civil, la edad, la filiación, la apariencia personal y la enfermedad o discapacidad. Las categorias a que se refiere el inciso anterior no podrán invocarse, en ningún caso, para justificar, validar o exculpar situaciones o conductas contrarias a las leyes o al orden público. Se considerarán razonables las distinciones, exclusiones o restricciones que, no obstante fundarse en alguno de los criterios mencionados en el inciso primero, se encuentren justificadas en el ejercicio legitimo de otro derecho fundamental, en especial los referidos en los números $4^{\circ}, 6^{\circ}, 11^{\circ}, 12^{\circ}, 15^{\circ}, 16^{\circ}$ y $21^{\circ}$ del artículo 19 de la Constitución Política de la República, o en otra causa constitucionalmente legitima" (artículo $2^{\circ}$ ).

A nuestro parecer, la Ley No 20.609 establece los siguientes requisitos para la procedencia de la acción de no discriminación arbitraria: a) la ocurrencia de una discriminación arbitraria, originada en una distinción, restricción o exclusión, motivada fundamentalmente en alguna de las causales denominadas por la doctrina como "sospechosas"; b) que tal discriminación arbitraria afecte el legítimo ejercicio de un derecho fundamental; y c) que tal afectación no se encuentre justificada en el ejercicio de otro derecho fundamental o en otra causa constitucionalmente lícita ${ }^{4}$.

Considerando lo anterior, la cuestión de Derecho a la que debió enfrentarse la judicatura en este caso se resume en las siguientes interrogantes. La primera: ¿La distinción realizada por el colegio afecta algún derecho fundamental de la

\footnotetext{
${ }^{3}$ Corte de Apelaciones de Concepción, 24 de octubre de 2014, Rol № 1009-2014.

${ }^{4}$ Cecilia Rosales expone los siguientes requisitos de procedencia de la acción (que se encuentran comprendidos en los puntos a) y b) de nuestra propuesta): "Deben concurrir copulativamente los siguientes elementos: a) que haya una distinción, restricción o exclusión cometida por un agente del Estado o un particular; b) Que carezca de justificación razonable; c) que cause privación perturbación o amenaza en el ejercicio legítimo de un derecho fundamental reconocido en la Constitución o en los tratados internacionales sobre derechos humanos ratificados por Chile y que se encuentren vigentes". RosalEs Rigol, Cecilia (2014). "La acción de no discriminación arbitraria”. En: Acciones protectoras de derechos fundamentales, Silva, María Pía y Henríquez, Miriam (Coords.), Santiago: LegalPublishing - Thomson Reuters, p. 279.
} 
demandante? Y la segunda, subordinada a la primera: ¿¿La consideración de la situación afectiva de una madre constituye una causal jurídicamente justificada de exclusión u obedece a una causa constitucionalmente legítima? ¿Ponderación o subsunción? La consideración de ambas cuestiones, y fundamentalmente la final, guiarán este comentario.

\section{1. ¿LA DISTINCIÓN REALIZADA AFECTA LOS DERECHOS} A LA EDUCACIÓN Y A LA LIBERTAD DE ENSENAANZA ALEGADOS?

La respuesta a esta interrogante fue abordada de manera parcialmente correcta por el tribunal de alzada de Concepción. En efecto, el considerando quinto de la sentencia en comento señaló que: "Por un lado, asiste a la alumna el derecho a la educación y a la libertad de enseñanza, en su faceta individual de elección del establecimiento educacional que se conforme con el desarrollo esperado de su personalidad humana".

Y decimos que la identificación del conflicto de derechos es sólo parcialmente adecuada puesto que de los dos derechos mencionados, el único que es de titularidad de la afectada es el derecho la educación, ya que el artículo 19 No 11 de la Carta Política es nítido al atribuir la titularidad del derecho a la libertad de enseñanza a los padres y a quienes desarrollen acciones de enseñanzas, no a los educandos.

La Constitución asegura, en el artículo 19 № 10, a "todas las personas" el derecho social a la educación, quedando claramente excluidas las personas jurídicas, pues tal derecho sólo puede ser predicable respecto de las personas humanas. Luego, la propia Carta, en el inciso tercero del mismo numeral, señala un titular determinado, los padres, quienes tienen el derecho preferente y el deber de educar a sus hijos 5 .

Distinta es la titularidad que la Constitución reconoce a la libertad de enseñanza, en la que corresponde distinguir la facultad que tienen las personas, humanas y excepcionalmente las jurídicas, para crear centros docentes (inciso $1^{\circ}$ del artículo 19 No 11) del derecho del que son titulares los padres para escoger el establecimiento de enseñanza para sus hijos (inciso $4^{\circ}$ del artículo 19 No 11 ). Por lo tanto, en relación con el caso y respecto de la libertad de enseñanza, es imposible que una estudiante sea potencial afectada de un derecho del cual no es titular. Con todo, cabe mencionar que este error en la lectura de la libertad de enseñanza no es infrecuente. Para muestra de ello basta revisar la misma inadecuada aplicación que del mismo derecho fundamental hizo la sentencia de primera instancia pronunciada este año en sede de protección en el caso conocido como "Tomas del Instituto Nacional"6.

Afortunadamente, la Corte no cometió el mismo error en la identificación del derecho alegado por el denunciado para justificar su conducta segregatoria. En el mismo considerando quinto señaló: "De otro lado encontramos el derecho

5 Aldunate Lizana, Eduardo (2003). "La titularidad de los derechos fundamentales". Revista Estudios Constitucionales, Año 1, No 1, pp. 187-201, p. 191.

${ }^{6}$ Corte de Apelaciones de Santiago, 18 de agosto de 2014, Rol No 39022-2014 acumulado No 39048-2014. 
del establecimiento educacional que se traduce en la libertad de ejecutar su proyecto educativo, en este caso orientado a la familia basada en el matrimonio religioso de los padres, por entender que es ese el terreno ideal donde se cultivan las virtudes que pretende plasmar en sus educandos".

Considerando entonces los requisitos de procedencia de la acción antes apuntados, la discriminación arbitraria se originó en una exclusión del colegio motivada por el estado civil de la madre de la niña, acto que afectó únicamente el legítimo ejercicio de su derecho a la educación. Corresponde entonces atender el cumplimiento del tercer requisito, esto es que tal afectación no se encuentre justificada en el ejercicio de otro derecho fundamental o en otra causa constitucionalmente lícita. Analizaremos este asunto a continuación.

\section{2. ¿LA CONSIDERACión DE La SITUACIÓN AFECTIVA DE LOS PADRES CONSTITUYE UNA CAUSAL JURÍDICAMENTE JUSTIFICADA DE EXCLUSIÓN? ¿PONDERACIÓN O SUBSUNCIÓN?}

En la segunda cuestión de Derecho planteada, la Corte no es, por desgracia, más precisa ni rigurosa. Ante la reflexión de si la libertad de enseñanza comprende la no aceptación de una alumna en base a las opciones afectivas de su madre, el tribunal de alzada anunció un razonamiento complejo fundamentado en la conocida técnica de la ponderación, pero sin explicarlo, considerando además en su aplicación derechos previamente no identificados como parte del conflicto, como es el caso de la "libertad de religión y de culto".

En la parte final del mismo considerando quinto se revela este pretendidamente complejo, pero en la práctica confuso, razonamiento: "Ante la colisión concreta planteada debemos realizar una ponderación de los derechos o principios fundamentales en conflicto, haciendo prevalecer el derecho a la educación de la niña por sobre la libertad de enseñanza, de religión y de culto de la persona jurídica propietaria del establecimiento educacional, ya que en el caso específico que se juzga, el nivel de afectación que implica la reincorporación de la alumna al colegio para el ejercicio de las libertades aludidas de la entidad denunciada no es relevante, incluso puede calificarse de marginal, en todo caso insuficiente para desplazar su derecho a la educación en el establecimiento elegido por su madre, como aquel lugar apto para el pleno desarrollo de su personalidad".

Como es sabido, el empleo de insumos provenientes de una teoría de la interpretación jurídica de índole principialista reclama al sentenciador un sólido y completo ejercicio argumentativo. Lo anterior supone la exposición de razones contundentes en dos ámbitos. Primero, una justificación del empleo de un método específico de solución de conflictos entre derechos fundamentales y no otro. Estajustificación es imprescindible si la propia ley que se aplica nada dice al respecto, máxime si la doctrina nacional aún se debate sobre la finalidad del inciso $3^{\circ} \mathrm{del}$ artículo $2^{\circ}$ de la Ley Zamudio. 
En efecto, algunos autores han afirmado que este inciso "pareciera contener una presunción de razonabilidad" cuando la distinción se justifica en el ejercicio legítimo de otro derecho fundamental ${ }^{7}$; otros que esta ley estaría creando una suerte de jerarquía de derechos, donde la no discriminación sería un derecho de segundo orden que quedaría siempre subordinado a otros derechos fundamentales expresamente enumerados en el inciso $3^{\circ}$ en comento ${ }^{8}$. Además, cabe preguntarse si en este caso se habría arribado a una solución distinta subsumiendo los hechos en los derechos invocados. A nuestro juicio, el resultado hubiese sido el mismo, pues resulta difícil sostener que las facultades asociadas a la libertad de enseñanza o a la libertad de religión o culto -como confusamente denomina a estas últimas la propia Corte- incluyen la posibilidad de seleccionar estudiantes en base a la situación afectiva de sus padres

Y, en segundo lugar, la opción por un modelo de razonamiento jurídico hace esperable que su utilización implique la concurrencia de todos sus elementos o etapas. En el caso de la ponderación, la evaluación de la idoneidad, necesidad y proporcionalidad en sentido estricto de la medida. De lo contrario, la decisión jurisdiccional corre el riesgo denunciado -con justa causa- por los numerosos detractores del principialismo: el ocultamiento de la discrecionalidad bajo el manto de técnicas pretendidamente científicas.

En la sentencia de marras, la solución al conflicto de derechos se produce en breves y erráticas líneas contenidas en el considerando quinto tantas veces citado y que en su última parte agregó: "Los niveles de afectación del derecho a la educación, dada la negativa a reincorporarse como alumna de enseñanza básica en el establecimiento, superan la molestia sufrida en las libertades anotadas de la institución educacional, sobre todo si se tiene en cuenta que la madre de la menor y su actual pareja estaban dispuestos a contraer prontamente matrimonio".

Lo anteriormente expresado es de cierta relevancia a propósito de esta ley, particularmente a efectos de la aplicación del test de proporcionalidad. La ponderación supone la evaluación del impacto que causaría la hipotética preferencia de

\footnotetext{
${ }^{7}$ José Manuel Díaz de Valdés sostiene que el legislador le estaría diciendo al juez: cuando se utilice una "categoría sospechosa", en lugar de realizar un examen de razonabilidad (que es lo que ordena el artículo $2^{\circ}$ inciso $1^{\circ}$ ), usted debe verificar que esa conducta no se justifique: i) por constituir el ejercicio legítimo de otro derecho, o ii) por otra "causa constitucionalmente legítima". En la primera hipótesis, el juez ya no debe atender a la razonabilidad de la distinción en sí, sino a determinar qué es el ejercicio legítimo del otro derecho (el foco ya no está en la igualdad y la no discriminación). Díaz DE VALDÉs, José Manuel (2013). “Es la Ley Zamudio verdaderamente una Ley General Antidiscriminación?”. Revista Actualidad Jurídica, No 28, p. 284.

${ }^{8}$ Iván Díaz expresa que en la Ley No 20.609 el derecho a no ser discriminado aparece subordinado a cualquier otro derecho fundamental y a cualquier bien constitucional, desde que la colisión entre aquella y estos últimos es resuelta directamente por la ley de manera incondicionada a favor de tales derechos y de tales bienes. Esto se hace por la vía de sostener, en la propia ley, que desaparece la falta de razonabilidad en la distinción si la misma se funda en el ejercicio legítimo de algún derecho fundamental o de cualquier causa constitucionalmente legítima; DíAz GARCíA, Iván (2013). "Ley chilena contra la discriminación. Una evaluación desde los derechos internacional y constitucional”. Revista Chilena de Derecho, Vol. 40, No 2, p. 656.
} 
un derecho en perjuicio de otro. Se trata de un ejercicio adversarial abstracto -a partir de hechos- entre dos derechos. (No entre uno y varios, como un pasaje de la sentencia en comento anuncia, de ahí la relevancia de identificar cuáles son los dos derechos realmente concurrentes en el caso). Y para evaluar la satisfacción de los elementos de este examen (idoneidad, necesidad y proporcionalidad en sentido estricto) siempre se requiere identificar al derecho en cuya virtud se pretende restringir el ejercicio del otro en colisión.

Cuando este análisis se desarrolla en sede de protección la identificación de los roles desempeñados por los derechos en pugna -fundante de restricción u objeto de potencial restricción- es relativamente sencilla. El derecho invocado por el sujeto activo de la acción cautelar opera generalmente como candidato a fundamento suficiente para la restricción del derecho invocado por el sujeto pasivo. Empero, en el caso de la Ley No 20.609 el eventual conflicto de derechos surge ante la invocación del denunciado de un derecho fundamental o causa constitucionalmente lícita, invirtiéndose el orden antes indicado. Es entonces la justificación esgrimida por el denunciado la que opera como hipotética razón fundante de la potencial restricción al derecho cuya afectación es reclamada.

Finalmente, el acto de discriminación arbitraria de autoría del colegio no puede justificarse en el supuesto ejercicio legítimo de derechos cuyo contenido no comprende las facultades aludidas. Entonces, de sentencias como esta, surgen más inquietudes que conclusiones. Entre ellas la que intitula este comentario, además de las ya mencionadas: ¿Por qué la Corte se inclina por la ponderación para resolver conflictos de esta índole? 